\title{
Modeling future heat pump integration in a power radial
}

\author{
Konstantin Filonenko $^{1} \quad$ Mikkel Copeland $^{2} \quad$ Klaus Jespersen $^{2} \quad$ Christian Veje $^{1}$ \\ ${ }^{1}$ Center for Energy Informatics, University of Southern Denmark, Denmark, $\{k f i$, veje $\} @ m m m i . s d u . d k$ \\ ${ }^{2}$ EWII Energi A/S, Denmark, mico@teknologisk.dk, klj@slukefter.dk
}

\begin{abstract}
This paper considers integration of heat pumps in Danish low-voltage residential power distribution network, hereafter referred to as "radial", providing a data-driven case study for the electrical package of the Modelica Buildings library. The loads in the distribution grid for year 2030 are estimated based on the requirement of fully sustainable energy system by the year 2050. Combined with local consumption, the total system model is validated by measuring mains transformer signal at the chosen radial. The maximum cable capacity is compared to future current flow estimations for a 2030 grid, simulated based on a specific official Danish scenario. The study shows, that there is no threat to the network cables, if only heat pumps are integrated. However, when maximum load is applied to the grid, the values of cable currents are relatively close to the limit, which may complicate integration of other technologies. The results point at recommendations for safety measures to protect electric lines during periods of rapid technological development.

Keywords: Buildings Library validation, Danish electric grid, heat pumps, photovoltaics, sustainable energy, distributed generation, electric power distribution
\end{abstract}

\section{Introduction}

\subsection{Motivation}

The Danish Energy Agency expects the heat production from heat pumps to reach $2265 \mathrm{GWh}$ in 2030 equivalent to $23 \%$ of the total residential heat demand with almost linear increase over time (Energistyrelsen, 2018; Energistyrelsen, 2018a). Integration of heat pumps in the existing traditional electrical system is supposed to increase energy efficiency compared to fossil fuel-based heating sources (Bloess, Schill, et al., 2017), e.g. boilers in Denmark (Petrović and Karlsson, 2016; Nielsen, Morales et al., 2015).

However, new installations may compromise grid safety, if the increased load exceeds capacity of distribution lines designed at the previous technological stage. Similarity of heat pump control settings in different households can lead to cumulative dynamic effect of simultaneous heat consumption resulting in high peak loads in the electricity grid. Transients will, therefore, play an important role in determining cable capacity limit which should be maintained to avoid damages.

On the other hand, heat pumps can increase flexibility of the distribution grid by postponing heat production when utilizing the heat storage in buildings (Fischer and Madani, 2017). As a result, one consumer's production can be shifted in time to match another consumer's consumption, thereby reducing the overall peak. Realtime model predictions may play, in this case, an important role for controlling power flows in the distribution grid and mitigating simultaneity effect.

This imposes requirements on model complexity/accuracy and its computational efficiency. Simultaneous production and consumption require that the bidirectional power flows are considered. Optimized control requires that the model is either black-box or lower-order grey-box to minimize the response delay. It is however desirable to have a validated white-box model available for comparison to ensure that no overfitting occurs when estimating the reduced-order model parameters and that it can be applied outside the training data range.

\subsection{State of art}

Modelica Buildings library has functionality for developing computationally efficient grey-box models of multi-energy systems (Lawrence Berkeley National Laboratory, 2019). The electrical package is suitable for simulating networks with bidirectional power flows and for optimization and control combining different energy dynamics in the same model (Bonvini, Wetter, and Nouidui, 2014).

Other Modelica libraries, capable of simulating electric distribution grids are IDEAS, PowerSystems, IPSL, OpenIPSL, ModPowerSystems, ObjectStab, PNlib, Electric Power Library (Winkler, 2017; Franke and Wiesmann, 2008). However, only Buildings and IDEAS contribute to the IBPSA library, which aims to standardize district energy simulation and optimization and integrate modeling with GIS data handling.

On the other hand, commercial Modelica libraries (Electric Power Library, Wind Power Library) and nonModelica proprietary tools (DIgSILENT PowerFactory, POWERSYS EMTP-RV, PSCADTM, Siemens 
PSS/ER ${ }^{\circledR}$ ) restrict exchange of validated models and complicate their use for model predictive control.

For this reason and due to availability of an easily comprehensible example (Wetter, Bonvini, et al., 2015), the electrical package from Buildings is chosen here to build a validated multi-energy white-box model with bidirectional power flow between prosumers and the main transformer. This model reuses components from Buildings.Electrical with minor modifications (Copeland and Jespersen, 2019).

\subsection{Aim of research}

The models of the building electrical systems from IDEAS package including converters and adapters are somewhat more detailed for needs of the local distribution system operator (DSO) when estimating the consumption and testing network capacities. Buildings library, on the other hand, does not include a component representing an internal electrical system of the consumer. Additionally, no system-level experimental model validation of electrical package is known to the authors. Few examples considered in the above library descriptions did not present any time-varying experimental validation. Therefore, the three goals set in this work are to

1. Develop a component responsible for the interaction of DSO and electricity consumer (not available in literature) combining loads for traditional household appliances and new technologies (heat pumps) with production from local energy sources (photovoltaics).

2. Compare the output of a data-driven model of the radial in a Danish residential area to measurements of the mains transformer signal obtained from the DSO during March 2019.

3. Apply the model to estimate the future current flow as a result of future network development, when more and more heat pumps are integrated to achieve the energy sustainability goals for 2050 established by Danish government.

\section{Cable box model}

\subsection{Concept}

This paper considers an important aspect of interaction between the DSO and residential consumer electrical subsystem through an interface called here a cable box (kabelskab in Danish electric sector). The cable box is a simple cabinet with a busbar, providing certain services to the consumer (ABB, 2020). It usually stands by the side of the pavement close to the households it serves and includes fuses and cable connectors. To understand the purpose of the cable box, it should be considered within the context of the overall power distribution system.
The transformer maintained by the DSO converts electric power from $10 \mathrm{kV}$ to $0.4 \mathrm{kV}$ to be distributed to several districts each via its own supply cable owned by the DSO. To clarify this structure, the term radial is used for each network emphasizing that it extends from the transformer along with other radials attached to the same transformer. The radial may be spilt several times and have any topology accepted for electric distribution networks. Several cable boxes are located along the radial and terminate the supply to the consumers. DSO is responsible for delivering the power only to the cable boxes, so it could be said that the cable box encapsulates the part of electrical system, for which consumers are solely responsible.

\subsection{Implementation}

In the considered case, a cable box connects consumers (typically, 3 to 4 households per cable box in Denmark) to a distribution line aggregating their power flows in either direction. For this reason, the cable box model seems to be the most appropriate building block for the Danish low-voltage distribution network model.

It is implemented here as a class extending classes from electrical package of Buildings Modelica Library constructed in the way similar to the Power Systems Library (Franke and Wiesmann, 2014) and Electric Power Library (Modelon, 2019). The package relies on overdetermined connectors to represent bidirectional power flows (Franke and Wiesmann, 2014). The replaceable phase system within a connector is analogous to the replaceable medium used by Modelica.Fluid library to model generic fluid flow (OpenModelica, 2019).

The implementation of the cable box component is shown in Figure 1. Both traditional and heat pump loads shown in the figure with their time tables extend Buildings.Electrical.AC.ThreePhasesBalanced.Loads, while the photovoltaic (PV) class instantiated three times extend from Buildings.Electrical.AC.OnePhase.Sources.PVSimpleO riented. The instances represent different orientations of the PV cells with respect to direct, diffuse and reflective irradiation. Both components are connected to the distribution grid via the one-phase terminal.

The parameter interface of the cable box shown in Figure 2 includes the names of the files containing time series for traditional and heat pump loads and the parameters of the PV cell: area and orientation. The PV model for each orientation is based on the total PV surface area $\mathrm{A}$, active area fraction $\mathrm{f}$, as well as module and $\mathrm{DC} / \mathrm{AC}$ conversion efficiencies, $\eta$ and $\eta \mathrm{c}$, and calculates the total electric power produced by the PV:

$$
P=I_{s} A f \eta \eta_{c}
$$

The total irradiation $I_{S}$ is supplied as an input to the component and is composed of three time series corresponding to the direct, diffuse and reflected irradiation. The traditional and heat pump electric 
systems are approximated by the linearized loads with fixed power factor of 0.98 and variable power supplied externally as a time series discussed in the next section.

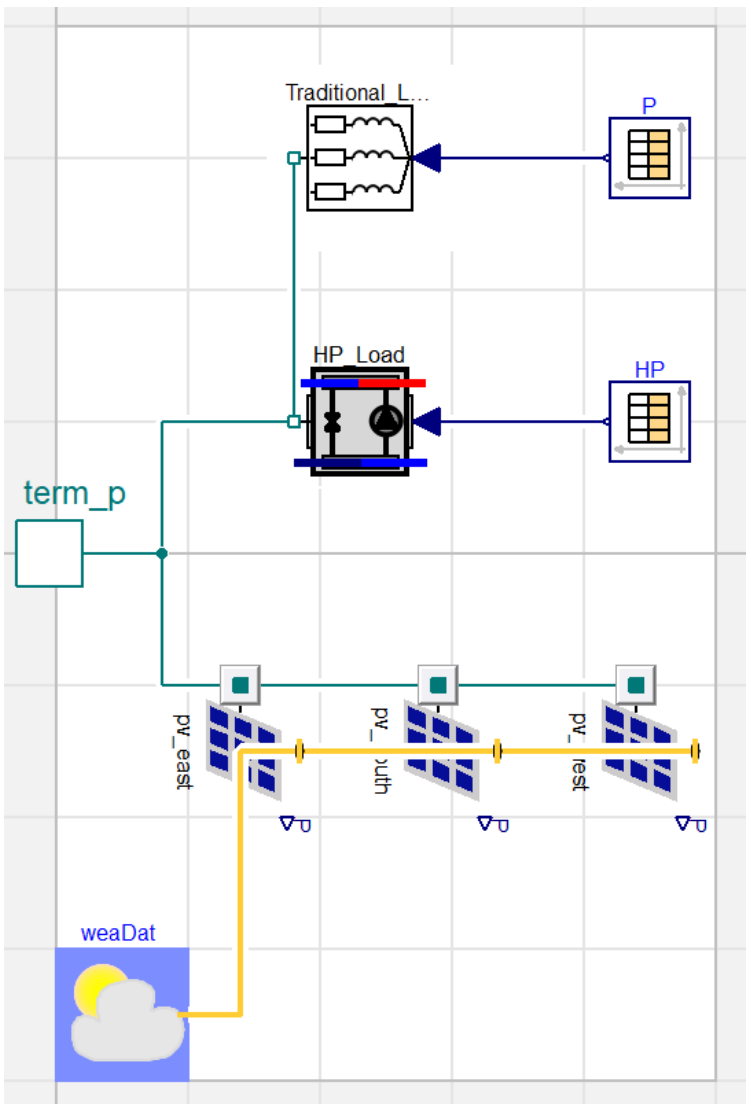

Figure 1. Modelica model of a residential cable box

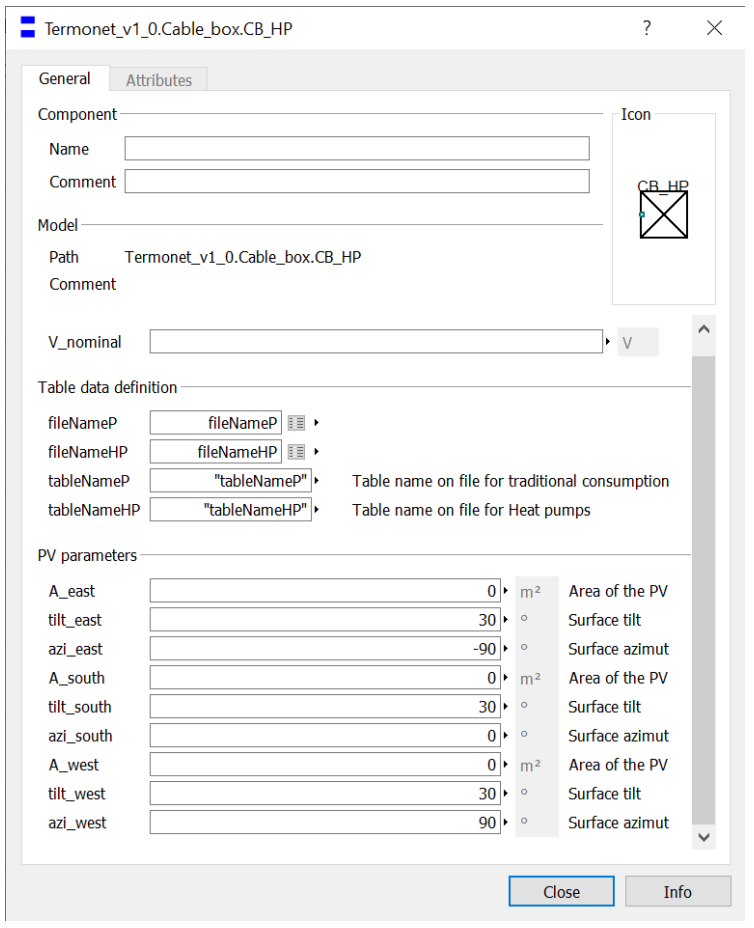

Figure 2. Parameter dialog of the cable box model

\subsection{Verification}

To ensure, that the sub-models provide reliable representation of the real cable box, they are verified in Figure 3 and Figure 4 against Matlab computations relying on analytical formulas and the following relation between the total current I, power factor pf and nominal grid voltage U (Copeland and Jespersen, 2019):

$$
I=\frac{P}{p f U}
$$

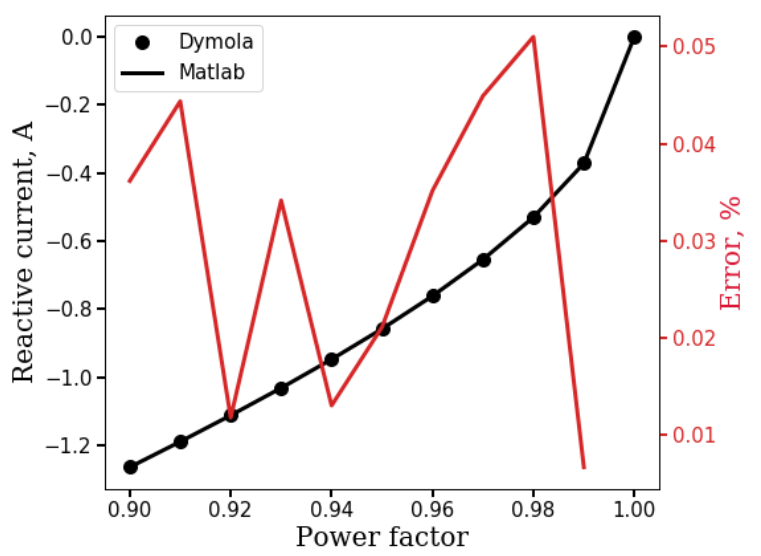

Figure 3. Verification of the load component.

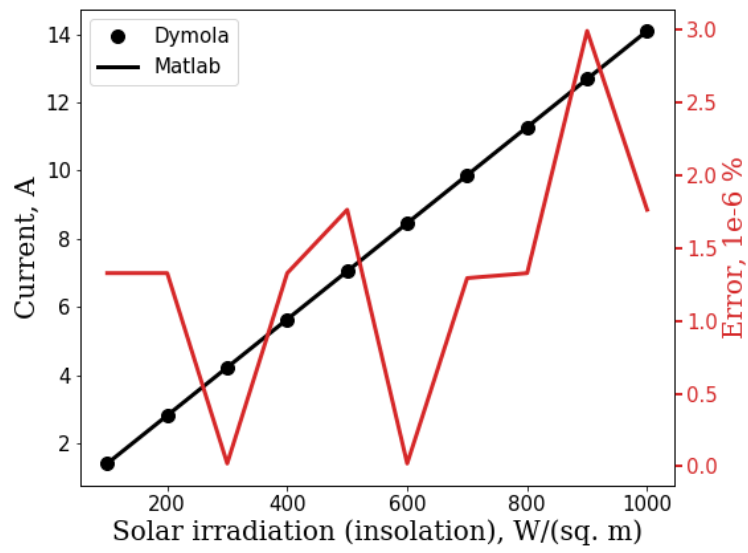

Figure 4. Verification of the PV component

Load calculations are compared in Figure 3, where the verification of the load component is done by varying the power factor in the range from 0.9 to 1 and calculating the reactive current from the total current and the power factor:

$$
I_{r}=I \sin (\operatorname{acos}(p f))
$$

To calculate $I, P$ is set equal to the nominal power of the grid in Eq. (1). The load performs as expected with an error magnitude of order $1 \mathrm{E}-2 \%$.

The objective of the PV verification shown in Figure 4 is to ensure that the output current from the component Buildings.Electrical.AC.OnePhase.Sources.PVSimple is as expected for a set of standard PV parameters. The active power in Eq. (2) is found from Eq. (1), and the 
irradiation base for the calculation is selected to be from $100 \mathrm{~W} / \mathrm{m}^{2}$ to $1000 \mathrm{~W} / \mathrm{m}^{2}$ to imitate real operation conditions. The error in this case is on the order of $1 \mathrm{e}-$ $6 \%$.

\section{System model}

The model of the radial shown in Figure 5 is constructed from the verified cable box (Section 2) and distribution components (Section 3.1) connected to the grid voltage source $-\mathrm{a} 10 \mathrm{kV}$ to $0.4 \mathrm{kV}$ transformer. It uses the actual
The distribution line model is verified in the range of the power factors from 0.9 to 1 in Figure 6 . The figure compares the voltage loss over the line segment obtained in Modelica simulation and the same voltage loss calculated in Matlab by using the formula

$$
\Delta U_{f}=I l_{c}(r p f+x \sin (\arccos (p f)))
$$

where $l_{c}$ is the length of the cable and $r$ and $x$ are characteristic resistance and reactance found in manufacturer datasheet. To calculate $I$ from Eq. (1), P has been set equal to the nominal active grid power.

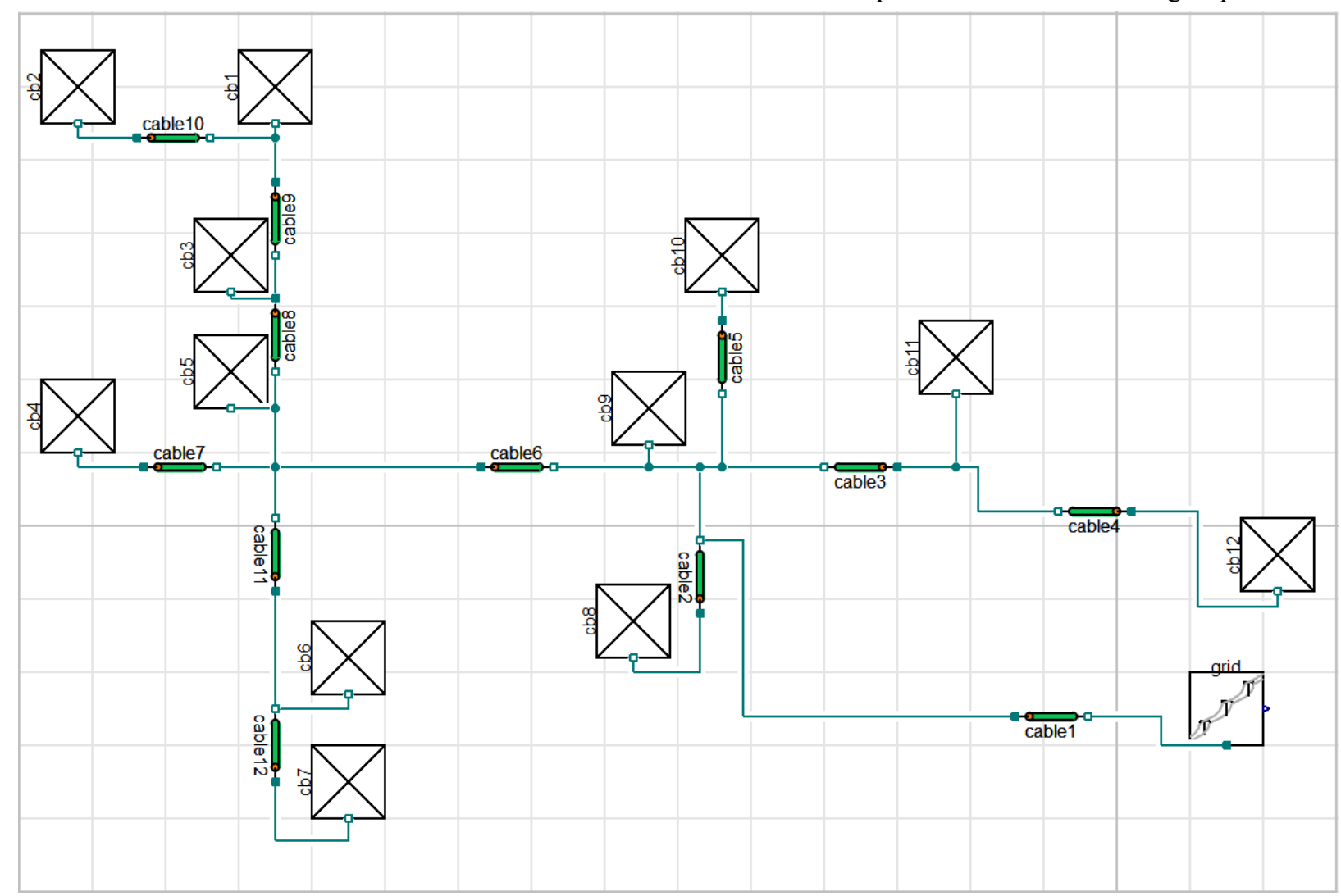

Figure 5. Model of the Danish radial (distribution cables: green cylinders, cable boxes: squares with diagonals drawn, grid: square with transmission lines drawn)

geographical layout to retain the visual information for future references. At the top level, the average load profiles and cable parameters are set by redeclaring the suitable replaceable records.

\subsection{Distribution}

To create a distribution line model, the class Buildings.Electrical.AC.OnePhase.Lines.TwoPortRLC is extended from Buildings library. The impedance of the distribution cables is calculated based on characteristic resistances and reactances taken from data sheet provided by the manufacturer. Both voltage and power losses are calculated in the model, however, the temperature dependence of the resistance is not accounted for in order to simplify the analysis.

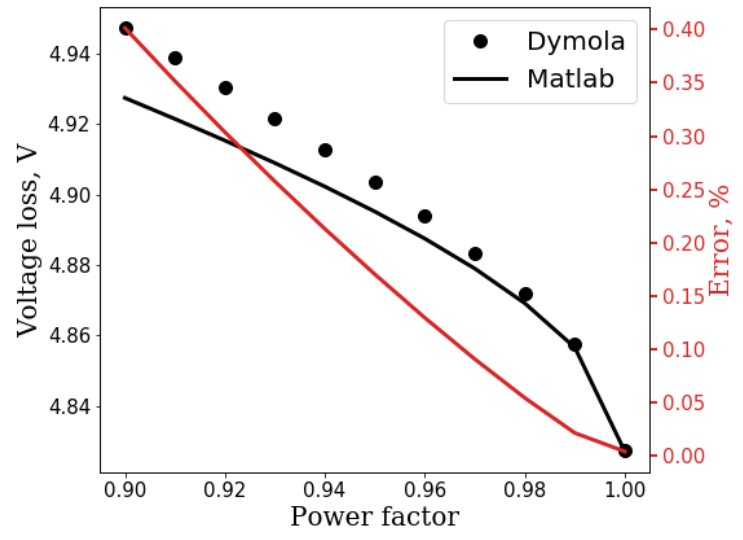

Figure 6. Verification of distribution line component 
The error in Figure 6 goes up to half of the percent for power factors close to 0.9 , but decreases below $0.1 \%$ in the range around 0.98 , which is the value mainly encountered in the actual system. It can be concluded that the model is accurate enough for the considered power factor values.

\subsection{Radial network topology and time series}

The model of the radial shown in Figure 5 accurately reproduces the topology of the DSO installation and includes two main nodes (1) connecting cable box cb5 to the distribution cables $6,7,8,11$ and (2) connecting cable box cb9 to the distribution cables 1, 2, 3, 5, 6 . Cable 1 serves as a supply cable from the main transformer.

To ensure that the radial is accurately represented in simulations, the seasonal consumption profiles for both traditional and heat pump loads were provided by the Danish DSO. The average of these electricity consumption time series for the traditional load is shown in Figure 7.

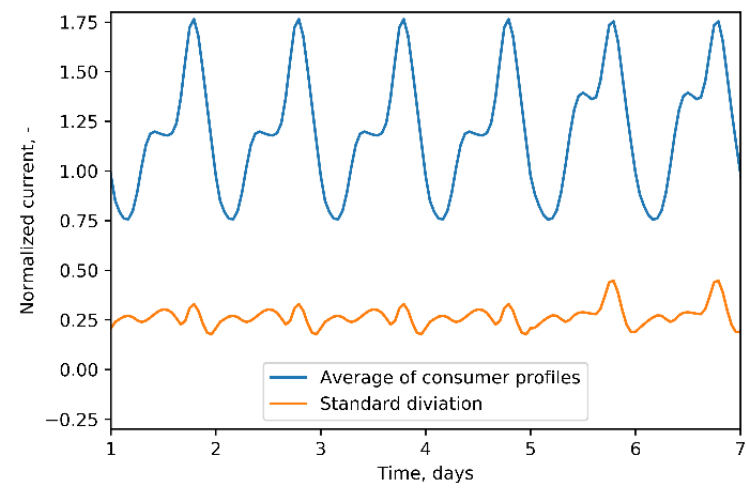

Figure 7. Average and standard deviation of the electrical consumption profiles used in modeling.

Each of the 30 individual profiles, which average is calculated in the figure, accounts for lighting, electronic devices, cooking, etc., but exclude domestic heating, since the radial is located in a district heating area. These profiles are intended for capturing a typical consumption pattern and are not used directly for a specific consumer in the model. The corresponding cable box loads are calculated as average values of the profiles of the consumers attached to the same cable box for each time moment.

The average takes into account the probability of each profile as corresponding to the common behavior pattern. Since the original consumption profiles represent real households, they are expected to be accurate with regards to the system construction and objectives of the model. The profiles, however, have limitations in terms of resolution since single occurrence peak values are leveled out by the mean calculation. From the analysis of the daily and varying seasonal profiles, the consumption showed the expected behavior of lower consumption in the summer compared to the winter. This consumption change depends on temperature and social behavior pattern in using lighting and electronic devices.

The heat pump electrical consumption $\mathrm{W}$ is defined by the domestic hot water (DHW) and space heating (SH) demands:

$$
W=(D H W+S H) / C O P
$$

where the heat pump coefficient of performance $(C O P)$ is calculated from the following regression formula obtained from manufacturer data:

$$
\begin{gathered}
C O P(T)=(-4.2 E-5) T^{3}+(4.9 E-4) T^{2} \\
+(6.9 E-2) T+2.4
\end{gathered}
$$

Correspondingly, the heat demand curve in Figure 8 is generated from two profiles with $\mathrm{SH}$ part produced by the heating degree day model

$$
S H=-0.16 T+2700
$$

and the DHW part calculated based on the $800 \mathrm{kWh} /$ year/person usage for 24 hour period and repeated throughout the year.

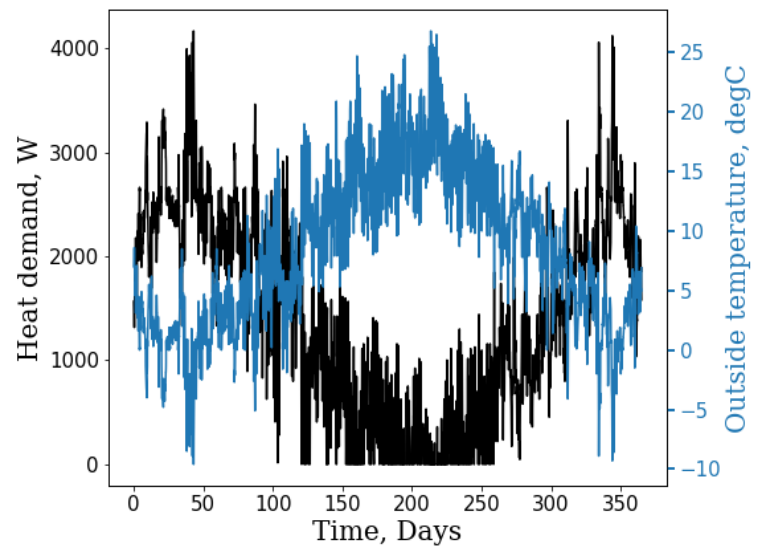

Figure 8. Modelled yearly heat pump demand profile

The time series for PV irradiation supplied to each PV orientation through the information connectors in Figure 1 are produced as a sum of the three contributions:

$$
I=I_{\text {dir }} R_{\text {dir }}+I_{\text {dif }} R_{\text {dif }}+I_{\text {ref }} R_{\text {ref }}
$$

where the direct, diffuse and reflected irradiation terms are governed by the following geometric relations (Copeland and Jespersen, 2019):

$$
\begin{gathered}
R_{\text {dir }}=\cos \left(\theta_{i}\right) / \cos \left(\theta_{z}\right) \\
R_{\text {dif }}=A_{I} R_{\text {dir }}+\left(1-A_{I}\right)(1+\cos (\beta)) / 2 \\
R_{\text {ref }}=(1-\cos (\beta)) \rho / 2
\end{gathered}
$$

with incident, zenith and horizontal tilt angles denoted by $\theta_{i}, \theta_{z}$ and $\beta$ and the surface reflectiveness and anisotropic index denoted by $\rho$ and $A_{I}$.

\subsection{Validation}

The model of a cable box is validated in Figure 9 against the current measured at the transformer station supplying the radial with power (grid component in 
Figure 5). The current, voltage, power factor, etc. of the system were continuously monitored in the period from March 8 to March 19, 2019 by the sensor located between the grid and cable 1 (the measurement data
2019), which did not anticipate considerable increase in either the traditional demand or the number of PV cells. It is therefore assumed that other loads and PV production remain unchanged and only the impact of

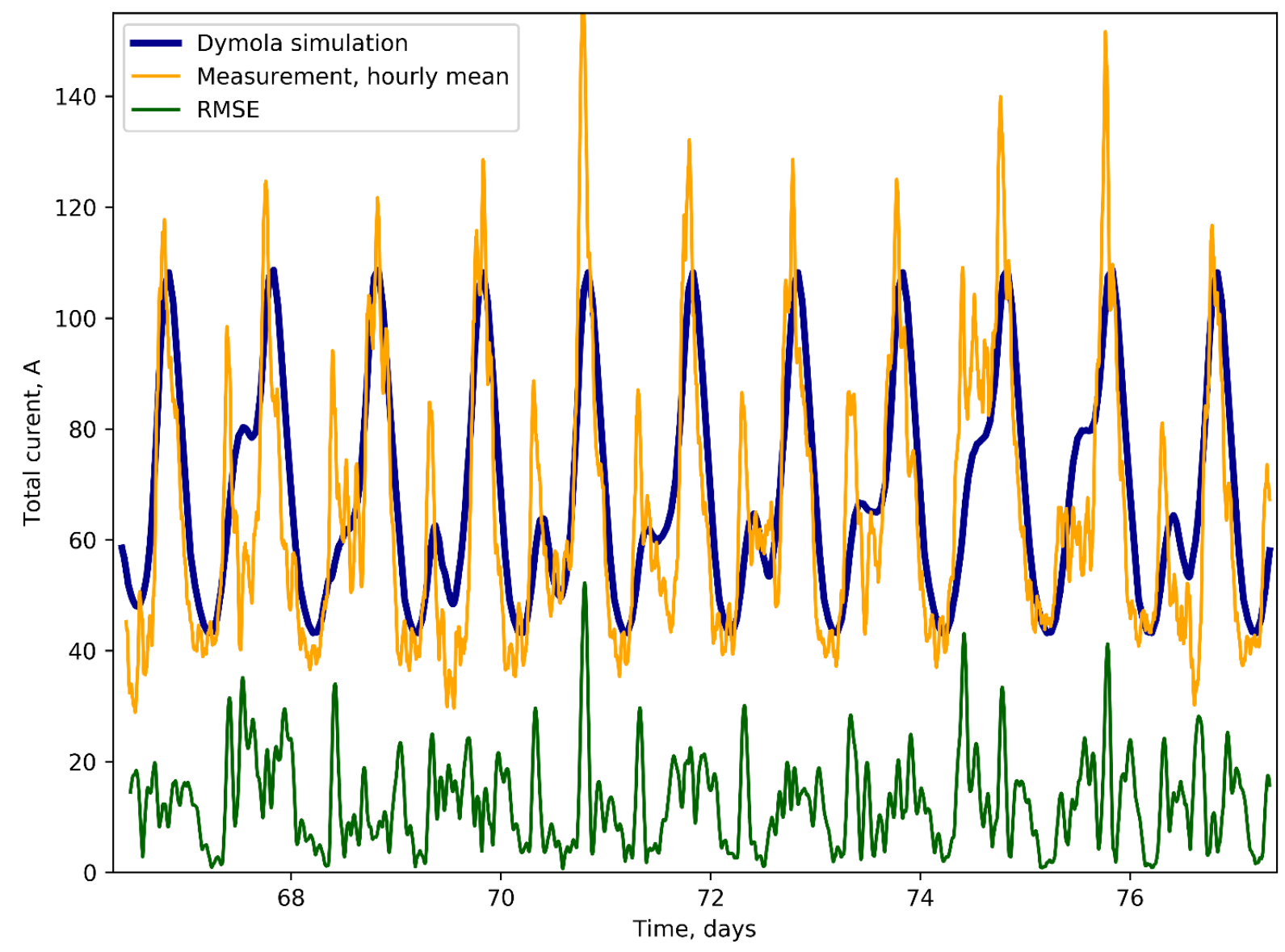

Figure 9. Validation of the radial model: comparison of the electric current values calculated in Modelica (blue curve) and the measured transformer current (orange curve) over two weeks of March 2019 and the root mean square error between the measured and calculated values (green curve).

outside of this time period is not available). Figure 9 shows the rolling average of the current measurements over the 1-hour window (orange curve), the total current simulated in Modelica (blue curve) and the root mean square error (green curve) between the two curves. Deviation of the simulated curve from the measured curve can be explained by the difference in assumed and actual ambient conditions during March 2019 resulting in a distorted PV production pattern. Additionally, the outliers seen in the figure are impossible to predict, since they depend on which appliances are connected to the cable box. In terms of the short-time load exertion on the transmission line, the peak has no real influence since the cables can handle much higher short-time current than the limit set by the providers.

\section{Results}

The heat pump integration scenario simulated here is proposed by Danish Energy Agency (Energistyrelsen, heat pump integration is considered according to the three scenarios summarized in Table 1: Static scenario is based on $0 \%$ forecast for the heat pump integration rate before the year 2030, which is not very probable, but will serve as a reference for other projections. Moderate increase scenario is based on DEA $23 \%$ projection for the electric heat pump units installed in Danish electrical system. To probe the system safety under the full heat pump penetration, the third, Maximum increase scenario is based on the 100\% projection, corresponding to the case where heat pumps supply heat to all consumers on the radial.

Table 1. Heat pump integration scenarios.

\begin{tabular}{|l|l|}
\hline Scenario & Projection \\
\hline Static & $0 \%$ \\
\hline Moderate increase & $23 \%$ \\
\hline Maximum increase & $100 \%$ \\
\hline
\end{tabular}


In Figure 10, the total currents through the supply cable 1 and the peripheral cable 8 (colored curves) calculated as $i_{\text {tot }}=\sqrt{\operatorname{Re}(i)^{2}+\operatorname{Im}(i)^{2}}$ are drawn for all three scenarios. These cables were chosen because they carry the largest current for their cable sizes. As could be expected, the currents through the cable 1 are larger by absolute value than the corresponding currents through cable 8, due to the fact that the supply line is exposed to all loads. Additionally, cable 1 has 3 PV installations of $5+3 \mathrm{~kW}, 5+3 \mathrm{~kW}$ and $5 \mathrm{~kW}$ while cable 8 has none. The capacities of cable 1 and cable 8 are shown in the figure as a dotted and a solid line, respectively.

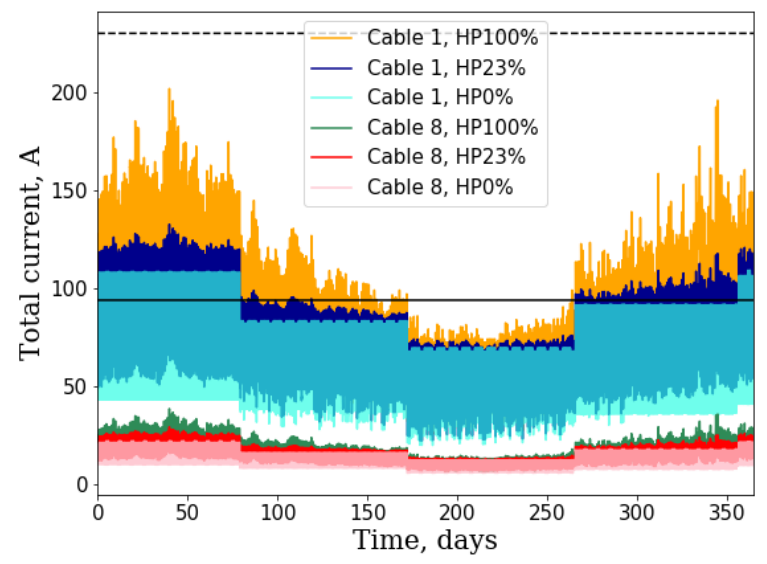

Figure 10. Heat pump penetration scenarios (year 2030). Cable capacities: cable 1 - 230 A, cable 8 - 94 A. HP0\% curves are made semi-transparent.

In the wintertime corresponding to the right quarter of the figure, the current in the reference static scenario has stable amplitude, changing only during the transition periods from colder to the warmer time. During these periods, the light availability for PV generation increases, thereby reducing the current required to power the cable boxes. The sharp drops in the figure occur, because the profiles for each new season are recalculated from previous datasets, which is a normal practice to be able to forecast and plan consumption. When the heat pump load is partially included within the Moderate increase scenario, this transition effect is superposed by the variation of the amplitude within each season due to direct influence of the increased heat pump capacity on the electric system.

Further explanation can be drawn from Figure 11, which includes the same currents having the same color codes as in Figure 10, but in February of the same year.

Larger heat demand in coldest period explains the global current peak in February for Moderate and Maximum increase scenarios. However, in the latter case, the system is more sensitive to the temperature variations, and consumption is increased due to reduced heat pump COP at lower ambient temperatures and larger installed heat pump capacity. The more tangible amplitude modulation can be attributed to the effect of coincidence of the heat demand events in response to systematic reduction of the ambient temperature. This effect becomes stronger, when larger number of consumers chose the same heating strategy in the cold period. Since in present study, the simplest strategy is implemented for all active consumers, the increase of their number leads to an unequivocal effect of current fluctuations following the consumer heat consumption.

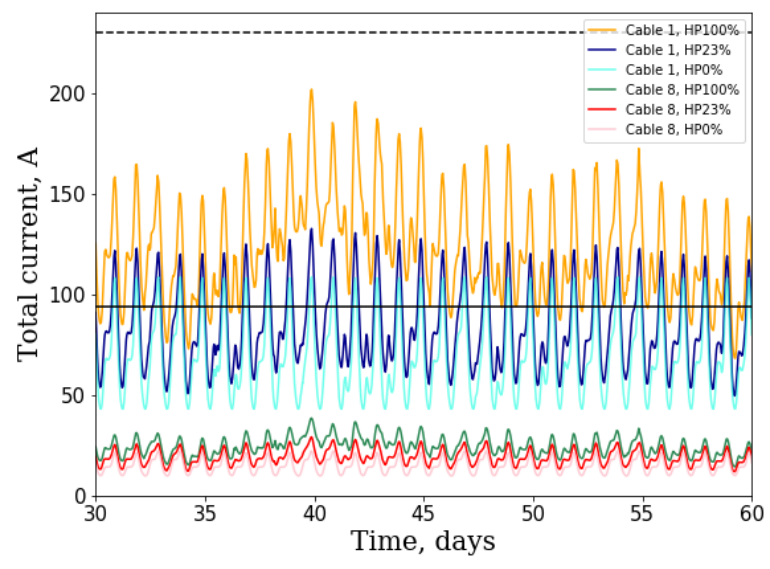

Figure 11. Total current in February 2030. The legend from Figure 10 applies.

In summer, on the other hand, the current values shown for all three scenarios in Figure 12 are close to each other, since less heating is needed, and the major part of the installed capacity is not used. The analysis of the peripherical lines (only Cable 8 is included in Figures) shows similar results with an increased current flow where heat pumps are installed and is discussed in the next section.

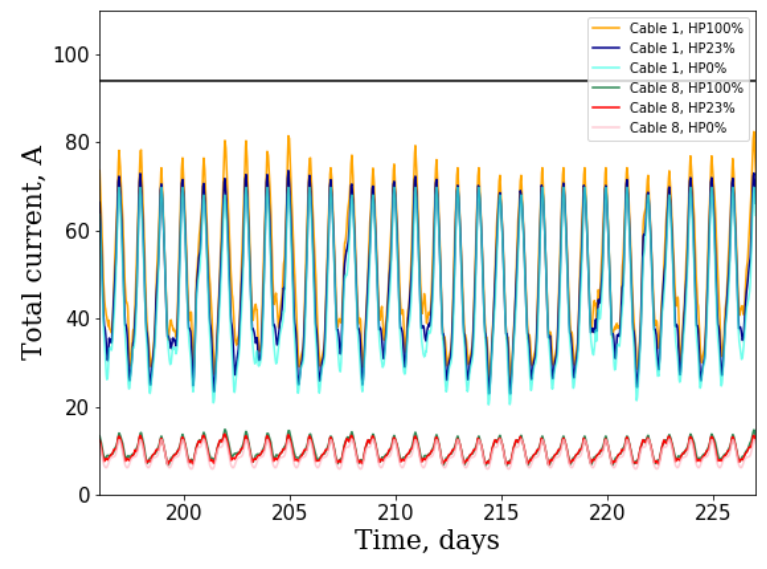

Figure 12. Total current from mid-July to mid-August 2030. Legend from figure 10 applies.

\section{Discussion and outlook}

Based on the obtained results, the simulated radial will perform satisfactorily for the 2030 projection offered by DEA, if only heat pumps are integrated. The supply cable 1 has the maximal mean current flow in winter equal to the half of the cable capacity in the Moderate increase scenario. The currents through peripheral 
distribution cable 8 and, therefore, all other peripheral cables are much less than its capacity limit.

If the radial is located in the area with $100 \%$ penetration of heat pumps (Maximum increase scenario), the current flow experiences significant seasonal fluctuations and the February peak exceeds 200 A. This and other peaks are relatively close to the capacity limit. Therefore, the integration of other technologies, such as electrical vehicles, may lead to an electrical signal exceeding the cable capacity.

The authors propose the following remedies, if the distribution currents exceed the installed capacities, which constitute the subject of future research on the topic:

1. Reduce simultaneity of consumption through load shifting and peak shaving

2. Introduce centralized model predictive control of heat pump's set points in different households to decrease the overall load on the system

3. Use flexibility of the thermal storage in buildings.

\section{Conclusion}

In this paper, the cable box component has been developed and validated against measurements at Danish residential radial. The component is applied to investigation of the integration of heat pumps in a typical Danish electric power distribution radial providing a data-driven case study for the electrical package of the Modelica Buildings library.

The maximum cable capacity is compared to future current flow estimations for 2030 grid simulated based on a specific Danish officials' scenario. Three simulations were performed to investigate the limit to which the distribution lines are stressed, if (1) no heat pumps are integrated in the households, (2) only $23 \%$ of the households adopted heat pumps and (3) if all households have heat pumps.

Based on the output data from Modelica and the subsequent analysis of the result, it can be concluded that there is no immediate threat to the cable capacity of the transmission lines in the radial. However, in the Maximum increase scenario, the values of cable currents are relatively close to the limit, which may complicate integration of other technologies. Therefore, to ensure the grid safety, the three solutions are proposed. The research and the model can be further modified to help the electric distribution system operators to estimate the grid load under known consumer behavior and the rapidly changing electric grid infrastructure.

Additionally, the use of Modelica as a modeling tool in the considered context offers fast and physically sound models of energy conversion systems like heat pump providing a potential benefit for dynamic simulation of sector coupling. The described model is purely electrical but can be relatively easily converted to the multienergy system by adding relevant mechanical, hydraulic and/or thermal components. This will allow to study the influence of heat pump control and heat storage flexibility in buildings on power grid performance, which is left for future work.

\section{Acknowledgements}

This manuscript emerged from the IBPSA Project 1, an international project conducted under the umbrella of the International Building Performance Simulation Association (IBPSA). Project 1 will develop and demonstrate a BIM/GIS and Modelica Framework for building and community energy system design and operation. The work was financed (research part) by the Danish Ministry of Energy, Utilities and Climate for the project DK Energy Live Lab - Vejle Nord (No. 20173451) and (participation) by Danish Energy Agency (Det Energiteknologiske Udviklings- og Demonstrationsprogram, EUDP) for the project IBPSA Project 1 CEI - SDU Participation (64018-0518).

\section{References}

ABB. Kabelskabe Combi-Line. Web-page containing the product description, 2020. url: https://new.abb.com/dk/om$\mathrm{abb} /$ vores-forretning/electrification-products/udendoerskapslinger/combi-line

Andreas Bloess, Wolf-Peter Schill, Alexander Zerrahn. Power-to-heat for renewable energy integration: A review of technologies, modeling approaches, and flexibility potentials. Applied Energy, No 9, pp. 1611-1626, 2018. doi: https://doi.org/10.1016/j.apenergy.2017.12.073.

Marco Bonvini, Michael Wetter, and Thierry S. Nouidui. A Modelica package for building-to-electrical grid integration. BauSIM 2014 Conference, Aachen, Germany, September 2014.

Jochen Cremer, Marco Pau, and Ferdinanda Ponci. Optimal Scheduling of Heat Pumps for Power Peak Shaving and Customers Thermal Comfort. In proceedings of 6th International Conference on Smart Cities and Green ICT Systems - SMARTGREENS 2017, 22nd-24th April 2017, Porto, Portugal, pp. 23-34.

Mikkel Copeland and Klaus Jespersen. Modeling the future distributed electricity grid. Master thesis, June 2019, University of Southern Denmark.

Energistyrelsen. Analyseforudsætninger til Energinet. 2018. url:

https://ens.dk/sites/ens.dk/files/Analyser/analysefoudsaetni nger til energinet 2018.pdf.

Energistyrelsen, Basisframskrivning 2018; Energi- og klimafremskrivning til 2030 under fravær af nye tiltag. 2018a. url: https:/ens.dk/sites/ens.dk/files/Analyser/basisfremskrivnin g 2018.pdf.

Rüdiger Franke and Hansjürg Wiesmann. Flexible modeling of electrical power systems - the modelica powersystems 
library. Proceedings of the 10th International Modelica Conference, 4(2):137-147, 2014.

David Fischer and Hatef Madani. On heat pumps in smart grids: A review. Renewable and Sustainable Energy Reviews, No 70, pp. 342-357, 2017. doi: https://doi.org/10.1016/j.rser.2016.11.182.

Lawrence Berkeley National Laboratory, Modelica Buildings library, 2019. https://simulationresearch.lbl.gov/modelica/

Modelon. Electric Power Library, 2019. url: https://www.modelon.com/library/electric-power-library/

Maria G. Nielsen, Juan M. Morales, Marco Zugno, Thomas E. Pedersen, Henrik Madsen. Economic valuation of heat pumps and electric boilers in the Danish energy system, Applied Energy, No 167, pp. 189-200, 2016. doi: https://doi.org/10.1016/j.apenergy.2015.08.115.

Hans Olsson, Martin Otter, Sven E. Mattson and Hilding Elmqvist. Balanced Models in Modelica 3.0 for Increased Model Quality. Proceedings Proc. of the 7th Modelica Conference, Bielefeld, Germany, March 2008. pp. 21-33.

OpenModelica. Modelica.Fluid.UsersGuide.Overview, 2019. url:

https://build.openmodelica.org/Documentation/Modelica.F luid.UsersGuide.Overview.html

Stefan Petrović and Kenneth Karlsson. Residential heat pumps in the future Danish energy system. Energy, No 114, pp. 787-797, 2016.2 doi: https://doi.org/10.1016/i.energy.2016.08.007.

Michael Wetter, Marco Bonvini, Thierry S. Nouidui, Wei Tian, and Wangda Zuo. MODELICA BUILDINGS LIBRARY 2.0. Proceedings of BS2015: 14th Conference of International Building Performance Simulation Association, Hyderabad, India, Dec. 7-9, 2015, pp. 387394.

Dietmar Winkler. Electrical Power System Modelling in Modelica - Comparing Open-source Library Options. Proceedings of the 58th Conference on Simulation and Modelling (SIMS 58) Reykjavik, Iceland, September 25th$27^{\text {th }}$, 2017. No. 138, pp. 263-270. doi: https://doi.org/10.3384/ecp17138263. 